\title{
Instrumento para mensuração do conhecimento tático declarativo no basquetebol feminino: validade de conteúdo da versão preliminar \\ Instrument for measurement of declarative tactical knowledge in women's basketball: validity of preliminary version contente \\ Instrumento de medición del conocimiento táctico declarativo en el baloncesto femenino: validez del contenido de la versión preliminar \\ *Cleiton Pereira Reis, *Arody Silva Correia Neto, **Matheus Marin de Freitas, *Harrison Assis Bizerra, *Elton César dos Santos, ***Adriana Amado Bazani, **** Luciana Thomazini de Araujo, *Juan Carlos Pérez Morales \\ *Universidade Federal de Minas Gerais Brazil), ** Esporte Clube Pinheiros (Brazil), ***Santo André/ABAPA (Brazil) **** Esporte Clube Corinthians Paulista (Brazil)
}

Resumo. O objetivo do estudo foi verificar as evidências de validade de conteúdo de cenas de vídeo extraídas de partidas oficiais de basquetebol para a construção da versão preliminar do Instrumento para Mensurar o Conhecimento Tático Declarativo para Basquetebol Feminino (IMCTD-BF). Editou-se, para o processo de validação de conteúdo, 70 cenas extraídas de jogos entre equipes que disputaram o LBF (Liga de Basquete Feminina). As cenas passaram pela análise de cinco peritos, treinadores (as) de basquetebol, nos quesitos: clareza da imagem, pertinência prática e representatividade do item. Calculou-se o Coeficiente deValidade do Conteúdo (CVC) para verificar a concordância entre os peritos, sendo o ponto de corte .80. Encontrou-se valores de CVC de .956 para clareza da imagem, .997 para pertinência prática e .960 para representatividade do item. Os procedimentos de validade ecológica e a concordância entre peritos, referentes à tomada de decisão e ao tipo de ataque, resultaram na seleção de 38 cenas. Conclui-se que foi possível construir a versão preliminar do IMCTD-BF a partir de 38 cenas que apresentaram evidências de validade de conteúdo.

Palavras-chaves: Basquetebol, Tomada de Decisão, Validação

Abstract. The aim of the study was to verify the evidence of content validity of video scenes extracted from official basketball matches for the construction of the preliminary version of the Instrument to Measure DeclarativeTactical Knowledge for Women's Basketball (IMCTD-BF). For the content validation process, 70 scenes extracted from games between teams that competed in the LBF (Women's Basketball League) were edited. The scenes were analyzed by five experts, basketball coaches, in the following items: clarity of the image, practical relevance and representativeness of the item. The ContentValidity Coefficient (CVC) was calculated to verify the agreement between experts, with a cutoff point of .80. CVC values of .956 were found for image clarity, .997 for practical relevance and .960 for item representativeness. The ecological validity procedures and the agreement between experts, regarding decision-making and the type of attack, resulted in the selection of 38 scenes. It is concluded that it was possible to build the preliminary version of the IMCTD-BF from 38 scenes that presented evidence of content validity.

Keywords: Basketball, Decision-Making,Validation

Resumem. El objetivo del estudio fue verificar la evidencia de validez de contenido de escenas de video extraídas de partidos oficiales de baloncesto para la construcción de la versión preliminar del Instrumento para Medir el Conocimiento Táctico Declarativo para el Baloncesto Femenino (IMCTD-BF). Para el proceso de validación de contenido se editaron 70 escenas extraídas de partidos entre equipos que compitieron en la LBF (Liga de Baloncesto Femenino). Las escenas fueron analizadas por cinco expertos, entrenadores de baloncesto, en los ítems: claridad de imagen, relevancia práctica y representatividad del ítem. Se calculó el Coeficiente deValidez de Contenido (CVC) para verificar la concordancia entre expertos, con un punto de corte de .80. Se encontraron valores CVC de .956 para claridad de imagen, .997 para relevancia práctica y .960 para representatividad de ítem. Los procedimientos de validez ecológica y el acuerdo entre expertos, en cuanto a la toma de decisiones y el tipo de ataque, dieron como resultado la selección de 38 escenas. Se concluye que fue posible construir la versión preliminar del IMCTD-BF a partir de 38 escenas que presentaban evidencia de validez de contenido.

Palabras clave: Baloncesto, Toma de Decisiones, Validación.

\section{Introdução}

O conhecimento é definido como o saber oriundo de experiências passadas, armazenado na memória de longo prazo de forma declarativa e processual (Sternberg \& Sternberg, 2016). O conhecimento tático

Fecha recepción: 16-07-21. Fecha de aceptación: 27-11-21

Cleiton Pereira Reis

cleitonpreis@yahoo.com.br se caracteriza pela base de informações que suporta a tomada de decisão, constituída por meio da prática (Gréhaigne \& Godbout, 1995; Kump, Moskaliuk, Cress, \& Kimmerle, 2015; Tenenbaum \& Medeiros Filho, 2017; García-Ceberino, Gamero, Feu, \& Ibáñez, 2020).

Considera-se o conhecimento tático declarativo (CTD) como a capacidade da atleta, quando questionada, de declarar, verbalizar a melhor opção a ser considerada frente a determinada situação do jogo que demanda 
tomada de decisão (McPherson, 1994; Anderson, 2005; Kump, et al., 2015). Tal conhecimento é demonstrado quando uma atleta explica corretamente ao treinador (a) qual é melhor opção em uma determinada situação do jogo, como por exemplo, explorar mais os arremessos de três pontos quando a defesa está muito afastada ou flutuada em uma determinada situação do jogo. Caracteriza-se o conhecimento tático processual pela base informacional que acarreta na execução de ações motoras, no caso do basquetebol feminino se manifesta por meio das ações que a atleta realiza durante uma partida (McPherson, 1994). Tal conhecimento é fruto do processo de agir, da prática cotidiana (Kump, et al., 2015). Verifica-se, no processo de tomada de decisão da atleta, a interação entre o conhecimento tático declarativo e o processual, por meio do treinamento. Tal interação é a base de conhecimento para a atleta de basquetebol conseguir ler o jogo (French \& Thomas, 1987; Tenenbaum \& Medeiros Filho, 2017).

Durante as fases de formação de atletas a avaliação sistemática do nível de rendimento tático representa uma ferramenta para o aprimoramento do processo de ensino-aprendizagem-treinamento (E-A-T) (Aburachid, Morales, \& Greco, 2013; Costa, Castro, Cabral, Morales, \& Greco, 2016). Verifica-se atualmente na área da Pedagogia do Esporte a necessidade de se validar instrumentos que permitam mensurar ações/ comportamentos realizados por atletas em diferentes modalidades esportivas (Aburachid, et al., 2013; Caicedo \& Vargas, 2020; Costa, et al., 2016; Llerena, Blanco, \& Hernández, 2020). Estudos mostram que intervenções com intuito de melhorar o CTD de atletas de basquetebol incrementa também o rendimento deles no ambiente de jogo (Alarcón, Vélez, Léon, Ortin, \& López, 2011; French \&Thomas, 1987; Iglesias, Rivas, Calvo, Gimeno, \& Álvarez, 2005; Pagé, Bernier, \& Trempe, 2019).

A validação de instrumento é um processo contínuo, composto por uma série de procedimentos, como validação de conteúdo, construto, confiabilidade (Furr, 2021; Pasquali, 2013, Rust, Kosinski, \& Stillwell, 2020). Gamero, González-Espinosa, Ibáñez e Feu (In Press) realizaram a validação de conteúdo de um instrumento que mensura o conhecimento tático declarativo no basquetebol por meio de representações gráficas, ou seja, cenas estáticas com figuras que representam situações de ataque. Assim na literatura não se encontrou instrumentos que mensuram o CTD no basquetebol por meio de cenas de vídeo, em movimento, de jogos de basquetebol oriundos de um processo robusto de validação de conteúdo. Apenas o estudo de Reis e Mora- les (2020) validou cenas de jogos de basquetebol, como evidências psicométricas robustas, quanto ao conteúdo para a construção de instrumento para mensurar o conhecimento tático declarativo. Porém, como o instrumento preliminar é composto por cenas de jogos de equipes masculinas, a construção do teste visa a aplicação em atletas do sexo masculino, uma vez que as ações das partidas oficiais acontecem em um contexto específico. No início das disputas competitivas, tanto nas categorias de base quanto na categoria profissional, ocorre a divisão por sexo na modalidade.

Vale lembrar que a velocidade das ações motoras dos atletas e o predomínio das ações técnico-táticas são diferentes entre as partidas masculinas e femininas. Considera-se, portanto, crucial realizar um estudo para a construção e validação de um teste de conhecimento tático declarativo com cenas extraídas de partidas de equipes femininas. Nesse contexto, justificamos a construção de um instrumento que mensura o conhecimento tático declarativo para jovens atletas do basquetebol feminino brasileiro que apresente indicadores psicométricos robustos e contribua para o aprimoramento do processo de ensino, aprendizagem e treinamento na categoria de base. Logo o objetivo do presente estudo é verificar as evidências de validade de conteúdo de cenas de vídeo extraídas de partidas oficiais de basquetebol para a construção da versão preliminar do Instrumento para Mensurar o Conhecimento Tático Declarativo para Basquetebol Feminino (IMCTD-BF).

\section{Método}

\section{Participantes}

Cinco treinadores de basquetebol, com média de idade de 49.68 \pm 7.07 , e tempo de experiência como treinador (a) 22.40 \pm 10.71, participaram do estudo como peritos. Os profissionais são formados em Educação Física e pós-graduados, maiores de idade e possuem mais de 10 anos de experiência como treinador. Desses profissionais, três são do sexo feminino e dois do masculino. Quatro deles trabalham no estado de São Paulo, um deles no estado do Espírito Santo. Todos já foram atletas da modalidade e exercem a profissão de treinador atualmente. Os profissionais possuem experiência em competições nacionais e internacionais, sendo que três deles já foram treinadores de seleções estaduais. Todos eles possuem títulos nacionais ou internacionais, bem como já passaram por cursos de formação de treinadores. 


\section{Cuidados Éticos}

Para a coleta de dados os peritos assinaram um Termo de Consentimento Livre e Esclarecido. Essa investigação foi aprovada pelo Comitê de Ética em Pesquisa da Universidade Federal de Minas Gerais com o número de protocolo CAAE: 16946719.2.0000.5149

\section{Procedimentos}

\section{Seleção das Cenas}

Selecionaram-se 70 cenas de oito jogos disputados nos anos de 2018 e 2019 entre equipes que disputaram o LBF (Liga de Basquete Feminina), principal competição profissional do basquetebol feminino brasileiro. A organização da LBF deu o apoio institucional para a realização do estudo. O pesquisador principal liderou uma equipe que analisou as cenas inicialmente, para os quesitos: qualidade da imagem e representatividade de uma situação em que o jogador no ataque com posse de bola deve tomar uma decisão no jogo de basquetebol (passar, infiltrar ou arremessar).

A equipe, para a edição das cenas, foi composta por três treinadores de basquetebol formados em Educação Física. Realizou-se um treinamento prévio com tal grupo de profissionais. Em situações de ataque posicionado ou contra-ataque, capacitou-se os pesquisadores para que editassem as cenas que representassem uma possível situação de tomada (s) de decisão pertinente ao jogo de basquetebol, a partir do atleta com a posse de bola na posição de tríplice ameaça. Depois desse processo, na edição, no momento da tomada de decisão do jogador com a posse de bola as cenas foram cortadas. As cenas apresentam uma duração aproximada de 12 segundos, pois se privilegiou a situação mais relevante do ataque. Para que as informações referentes ao jogo não interferissem na coleta de dados, introduziu-se uma tarja preta nas informações referente ao placar, período e tempo de jogo (Smeeton, Hüttermann, \& Williams, 2019).

Finalmente, congelou-se a imagem por três segundos. Logo após a cena se apresenta como uma tela preta, realizando-se assim a oclusão da imagem. Tal contexto permite que o participante recupere as informações recentes na cena, bem como perceba os sinais relevantes (Castro, Costa, Praça, Campbell, \& Greco, 2017; Raab, 2003; Reis \& Morales, 2020). Utilizou-se tais procedimentos de edição das cenas também no estudo de Reis e Morales (2020) para validação de conteúdo de cenas de jogos de basquetebol de equipes profissionais do basquetebol masculino.

\section{Análise dos dados}

Após os procedimentos de avaliação (qualidade e representatividade) e edição descritos anteriormente, as 70 cenas foram enviadas para o painel de cinco peritos para realização dos procedimentos de obtenção de evidências de validade de conteúdo. $O$ pesquisador principal explicou todos os procedimentos necessários para a avaliação das cenas, bem como forneceu a planilha para a análise. Cada um dos peritos avaliou a qualidade e a pertinência das cenas em relação ao construto conhecimento tático declarativo (Furr, 2021; Heale \& Twycross, 2015; Pasquali, 2013). Os peritos receberam um documento com as instruções e critérios para a avaliação das 70 cenas editadas a respeito aos quesitos referentes a clareza da imagem, a pertinência prática e a representatividade da cena.

Adaptou-se, para este estudo, o conceito de clareza de linguagem, proposto por Hernadez-Nieto (2002), para clareza de imagem. O termo clareza de linguagem diz respeito aos termos e a linguagem utilizada em cada um dos itens. Analisa se a forma de escrita e a redação apresentada são de fácil compreensão. Nesse sentido, tratando-se de um instrumento que utiliza cenas de vídeo extraídas de jogos oficiais de basquetebol, entende-se que a clareza de imagem se relaciona com a qualidade visual da cena, nitidez e possibilidade de enxergar claramente as ações do jogo na mesma. Outros estudos também empregaram o conceito de clareza de imagem no sentido de determinar a validade de conteúdo de cenas editadas a partir de partidas oficiais no tênis (Aburachid, etal., 2013), no voleibol (Costa, et al., 2016), no basquetebol (Reis \& Morales, 2020) e handebol (Ribeiro, Figueiredo, Morales, Nascimento, Porto, \& Greco, 2021).

Objetiva-se, mediante a pertinência prática, analisar se o item é representativo da situação tática a ser observada e se possui relevância para o quê o instrumento se propõe a mensurar (Hernadez-Nieto, 2002). Assim os peritos avaliaram, na perspectiva da pertinência prática, se a cena representa ou não uma situação adequada para a tomada de decisão no basquetebol, ou seja, se a ação apresentada na cena editada se refere a uma situação frequente e característica da modalidade, em que a atleta no ataque ou contra-ataque com bola deve tomar uma decisão. A representatividade do item considera o grau de associação entre a cena e modelo teórico, ao construto que pretende ser estudado (Hernadez-Nieto, 2002). Para tal, os peritos analisaram se a cena favorece a mensuração do conhecimento tático declarativo (CTD) no basquetebol. Nesse sentido, para 
tal aspecto, o perito vislumbra se a cena possui relação direta com o construto CTD, ou seja, se auxilia na avaliação de tal variável.

Recorreu-se, para a obtenção de evidências de validade de conteúdo, a uma escala de Likert de cinco pontos com iguais intervalos entre eles ( $1=$ inadequada; $2=$ pouco adequada; $3=$ aceitável; $4=$ adequada; $5=$ muito adequada). Portanto o painel de peritos atribuiu uma nota para clareza da imagem, pertinência prática e representatividade do item para cada uma das 70 cenas selecionadas.

Utilizou-se, a partir da nota do painel de peritos, o Coeficiente de Validade do Conteúdo (CVC), proposto por Hernández-Nieto (2002), para a avaliação dos seguintes quesitos: a clareza de imagem, pertinência prática e representatividade do item. A seguir os passos para o cálculo do Coeficiente de Validade do Conteúdo (CVC):

1) com base nas notas dos peritos, calculou-se a média das notas de cada item $(\mathrm{Mx})$ :

$$
M_{x}=\frac{\sum_{i=1}^{J} X i}{J}
$$

Onde $\sum$ xi representa a soma das notas dos peritos e J representa o número de peritos que avaliaram o item.

2) com base na média, calculou-se o CVC para cada item (CVCi):

$$
\operatorname{CVC}_{i}=\frac{M_{x}}{V_{\max }}
$$

Onde Vmáx representa o valor máximo que o item poderia receber.

3) realizou-se ainda o cálculo do erro (Pei), para descontar possíveis vieses dos peritos avaliadores, para cada item:

$$
P e_{i}=\left(\frac{1}{J}\right)^{J}
$$

4) com isso, o CVC final de cada item (CVCc) foi assim calculado:

$$
C V C_{c}=C V C_{i}-P e_{i}
$$

5) para o cálculo do CVC total do questionário (CVCt), para cada uma das características (clareza de linguagem e pertinência prática), utilizou-se:

$$
\mathrm{CVC}_{i}=\mathrm{MCVC}_{i}-\mathrm{Mpe}_{i}
$$

O Mcvci representa a média dos coeficientes de validade de conteúdo dos itens do questionário e Mpei, a média dos erros dos itens do questionário. Descartaram-se, para a sequência da validação de conteúdo, os itens (cenas) que não alcançaram o CVCc .80 para os quesitos avaliados. Verifica-se, por meio da escala de 0 a 1 , a seguinte classificação do CVC: menos de .80 , considera-se inaceitável; de .80 a .90 como aceitável; acima de .90 se considera como excelente a validade de conteúdo (Hernadez-Nieto, 2002).

\section{Validade Ecológica}

Comparou-se a melhor tomada de decisão descrita pelo painel de peritos no sentido de verificar a validade ecológica das cenas. Considera-se a cena valida ecologicamente quando a tomada de decisão mais adequada é considerada como a melhor opção no procedimento de hierarquização (conforme a avaliação e seleção das melhores tomadas de decisão e sinais relevantes) é a mesma ação realizada pelo atleta na situação real de jogo captada na cena de vídeo (Pasquali, 2007). Considera-se como validade ecológica quanto um instrumento mede ou tem correspondência com as situações reais que acontecem no ambiente real (Furr, 2021; Pasquali, 2007).

\section{Ataque Posicionado e Contra-ataque}

O painel de peritos também deliberou sobre a dimensão que cada cena representava, isto é, se a cena selecionada representa uma ação de ataque posicionado ou de contra-ataque. A partir do painel dos peritos foi possível verificar se a cena representa uma situação de ataque posicionado ou contra-ataque. Para isso, aplicouse, mediante a equação descrita a seguir, o cálculo da Concordância entre Observadores (CEO) (CasseppBorges, Balbinotti, \& Teodoro, 2010; Thomas, Nelson, \& Silverman, 2012):

$$
\mathrm{CEO}=\frac{\text { concordância }}{\text { concordância }+ \text { discordância }}
$$

$\mathrm{O}$ CEO $\geq .80$ indica adequados níveis de concordância, portanto, selecionaram-se as cenas que alcançaram esse valor na avaliação dos peritos referente ao tipo de ataque (posicionado ou contra-ataque).

\section{Avaliação e Seleção das Melhores Tomadas de Decisão e Sinais} Relevantes

Analisou-se, partindo das considerações dos peritos, as cenas referentes à hierarquização das tomadas de 
decisão, à justificativa e aos sinais relevantes percebidos. Via percepção, no ambiente esportivo, o participante consegue identificar pistas, sinais que podem ser relevantes ou não, que orienta esse indivíduo a escolher a melhor tomada de decisão (Tenenbaum \& Medeiros Filho, 2017). Em uma situação, por exemplo, em que a defesa não consegue cobrir todos os espaços o atacante com bola fica com um corredor livre (sinal relevante), sendo assim, a melhor tomada de decisão é infiltrar em direção a cesta (Raab, 2015; Reis \& Morales, 2020; Tenenbaum \& Medeiros Filho, 2017).

Requereu-se que os peritos determinassem, para cada um dos itens/cenas, as possíveis opções que a atacante com posse de bola poderia tomar conforme o contexto exposto no congelamento da cena. Após esse procedimento, requisitou-se aos peritos para que hierarquizassem todas as decisões elencadas, da mais adequada para a menos adequada, juntamente às respectivas justificativas. Para isso os peritos apontaram os sinais relevantes que perceberam durante a visualização da cena, isto é, perguntou-se para os peritos «O que a atleta com bola deve fazer? Por quê? Justifique suas escolhas a partir dos sinais relevantes ou pistas que observou na situação do jogo».

Mediante ao cálculo do CEO, definiu-se a concordância na tomada de decisão entre os peritos para cada um dos itens/cenas. Manteve-se apenas as cenas com CEO e» .80, sendo que as mesmas constituíram preliminarmente o gabarito. Por meio da técnica de análise temática (Minayo, 2012) se procedeu a análise de conteúdo das justificativas e identificação dos sinais relevantes referentes as cenas. Por fim, elaborou-se o gabarito com os itens/cenas que alcançaram CEO e» $80 \%$ de concordância nas escolhas ou respostas dadas pelo painel de peritos, relativo à melhor tomada de decisão e aos sinais relevantes.

\section{Resultados}

A Tabela 1 mostra que, das 70 cenas selecionadas inicialmente, excluíram-se sete cenas, para o critério clareza da imagem; e 10 cenas, para representatividade do item, por não alcançarem CVC e» .80. Das 17 cenas excluídas, duas cenas eram de contra-ataque e 15 de ataque posicionado. O resultado final do cálculo do CVC selecionou 53 cenas, sendo 15 de contra-ataque e 38 de ataque posicionado.

A análise temática das justificativas elaboradas pelo painel de peritos resultou na proposição dos sinais relevantes para cada uma das cenas, aprovados no
Tabela 1.

Resultados do Cálculo do CVC eferentes à Análise Teórica das Cenas

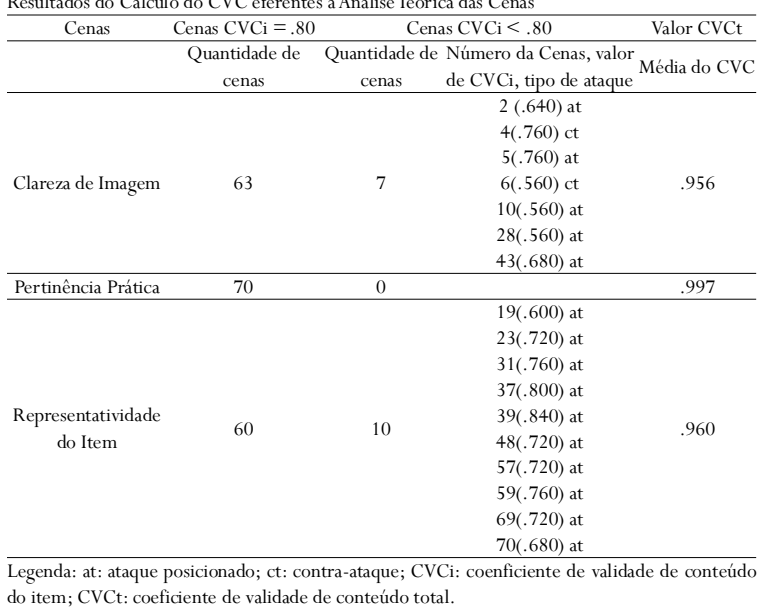

procedimento quanto à validade ecológica. Restaram assim 40 cenas, ou seja, em 13 cenas a melhor tomada de decisão considerada pelos peritos não aconteceu no ambiente real do jogo (validade ecológica). Permaneceram assim as cenas que alcançaram concordância absoluta entre a decisão do painel de peritos e a decisão do atleta na situação real de jogo. Outros estudos utilizaram o mesmo procedimento para avaliar a validade ecológica das cenas no basquetebol masculino (Reis \& Morales, 2020) e no voleibol masculino (Costa et al., 2016).

Das 40 cenas selecionadas após o procedimento de validade ecológica, 38 cenas alcançaram um valor de concordância na tomada de decisão dos peritos (CEO) e» .80 , sendo 15 de contra-ataque e 23 de ataque posicionado. As cenas 3 e 40, ambas de contra-ataque, o painel de peritos não concordaram completamente nas possíveis opções de tomada de decisão $(\mathrm{CEO}<.80)$. A Figura 1 ilustra o fluxograma do processo de validação de conteúdo das cenas.

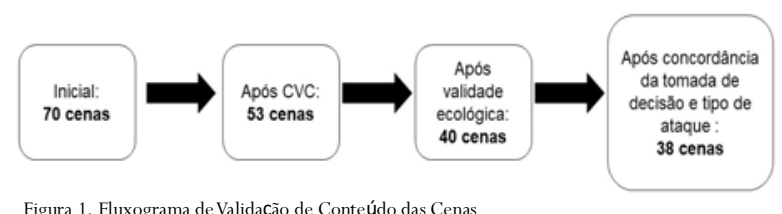
Legenda: CVC: Coeficiente de Validade de Conteúdo.

No que se refere ao tempo empregado para avaliação das atletas de basquetebol por parte das instituições esportivas, das 38 cenas avaliadas, selecionou-se 24 cenas no sentido de construir uma versão preliminar do Instrumento para Mensurar o Conhecimento Tático Declarativo para o Basquetebol Feminino (IMCTD-BF), de rápida aplicação, como duração aproximada de 50 minutos (Reis \& Morales, 2020). Descreve-se a seguir os critérios para a seleção das cenas. 
a) Um terço das cenas de contra-ataque, consideradas mais difíceis pelos peritos quanto ao reconhecimento dos sinais relevantes;

b) Cenas que apresentaram o maior número de possibilidades de tomada de decisão (respostas) $(n=2)$;

c) Quanto ao tipo de resposta validada pelos peritos para as cenas de ataque, ou seja, recorre-se para um equilibrio na quantidade de cenas que a primeira resposta está relacionada com o passe, a infiltração ou o arremesso. Um procedimento semelhante também foi realizado no trabalho de Reis e Morales (2020).

Na Tabela 2 se encontram as descrições das cenas:

\begin{tabular}{|c|c|c|}
\hline cena & tipo de ataque & tomada de decisão \\
\hline 7 & ataque posicionado & passe \\
\hline 9 & ataque posicionado & passe \\
\hline 13 & ataque posicionado & passe \\
\hline 15 & ataque posicionado & infiltração \\
\hline 17 & ataque posicionado & passe \\
\hline 25 & ataque posicionado & passe \\
\hline 29 & ataque posicionado & infiltração \\
\hline 32 & ataque posicionado & infiltração \\
\hline 33 & ataque posicionado & arremesso \\
\hline 35 & ataque posicionado & passe \\
\hline 36 & contra-ataque & infiltração \\
\hline 38 & ataque posicionado & infiltração \\
\hline 41 & contra-ataque & infiltração \\
\hline 42 & contra-ataque & arremesso \\
\hline 45 & contra-ataque & infiltração \\
\hline 49 & contra-ataque & passe \\
\hline 50 & ataque posicionado & arremesso \\
\hline 53 & ataque posicionado & arremesso \\
\hline 55 & ataque posicionado & arremesso \\
\hline 61 & contra-ataque & arremesso \\
\hline 63 & ataque posicionado & arremesso \\
\hline 65 & ataque posicionado & arremesso \\
\hline 66 & ataque posicionado & infiltração \\
\hline 68 & ataque posicionado & infiltração \\
\hline
\end{tabular}

\section{Discussão}

O objetivo do presente estudo foi verificar as evidências de validade de conteúdo de cenas de vídeo extraídas de partidas oficiais de basquetebol para a construção da versão preliminar do Instrumento para Mensurar o Conhecimento Tático Declarativo para Basquetebol Feminino (IMCTD-BF). Do total de 70 cenas selecionadas para as análises dos peritos, 17 cenas não alcançaram valores de CVC satisfatórios em um dos quesitos referentes à representatividade do item, pertinência prática e clareza da imagem. O cálculo do CVC é considerado como um processo de análise de conteúdo de fácil manuseio, que não necessita de aparatos complicados ou de um programa de computador sofisticado(Hernández-Nieto, 2002). Outros estudos que validaram cenas para testes de conhecimento tático declarativo também utilizaram o CVC para avaliar o conteúdo das cenas, como no voleibol (Costa, et al., 2016), no tênis (Aburachid et al., 2013) e no handebol (Leão, 2015).

O cálculo do CVC revelou que $75.41 \%$ das cenas
(53 cenas) alcançaram resultados satisfatórios no que se refere à clareza de imagem, pertinência prática e representatividade do item. A cenas que permaneceram demonstram evidências de qualidade e pertinência das cenas em relação ao construto a ser avaliado. No atual estudo se observou um CVCt acima de .95 para os critérios estabelecidos. Em um estudo para validar cenas de tênis verificou o CVCt acima de .89 (Aburachid et al., 2013). No voleibol outra investigação relatou CVCt para as cenas acima de 92 (Costa, et al., 2016). Compreende-se assim que, sobre a validade de conteúdo sobre cenas do basquetebol feminino, no geral, os peritos deram notas elevadas para os critérios: clareza de imagem, pertinência prática e representatividade do item.

Posteriormente, excluiu-se 13 cenas devido ao critério de validade ecológica, ou seja, a primeira opção de tomada de decisão validada pelos peritos não correspondia com o que foi feito no jogo em si. Das 40 cenas, foram aprovadas 38 referentes à concordância pelos peritos das possíveis tomadas de decisão e a hierarquização das opções. Destas 38 cenas, 23 foram consideradas de ataque posicionado e 15 de contra-ataque.

Recomenda-se que no final desse processo pelo menos 20 itens sejam validados (Pasquali, 2013). Tal contexto foi contemplado já que 38 cenas (54.29\%) mostraram evidências de validação de conteúdo. Tal aproveitamento se assemelha ao que foi alcançado em outro estudo, já que estudo de Reis e Morales (2020), ao validarem o conteúdo de cenas de jogos profissionais do basquetebol masculino aproveitaram 43 cenas (50.00\%) de um total de 86 cenas editadas originalmente. O processo de validação das cenas permitirá a construção de um, ou até dois instrumentos preliminares para mensurar o conhecimento tático declarativo no basquetebol feminino, já que investigações recentes utilizaram entre 11 e 20 cenas para mensurar essa variável no contexto esportivo (Aburachid et al., 2013; Castro et al., 2019; Leão, 2015).

Verifica-se que o coeficiente de validade de conteúdo, validade ecológica e coeficiente de concordância entre observadores são procedimentos pertinentes para estabelecimento da validade de conteúdo no processo de desenvolvimento e validação de instrumentos referenciados no construto. A análise teórica dos itens e do instrumento, no geral, possibilita examinar previamente se o instrumento em questão mede, no viés de conteúdo, o construto que se pretende mensurar (Cassepp-Borges et al., 2010; Furr, 2021; Heale \& 
Twycross, 2015). Um instrumento com validade de conteúdo é capaz de analisar uma amostra representativa de comportamentos dentro de um universo finito (Pasquali, 2010). O objetivo da validação de conteúdo é minimizar o erro potencial associado à operacionalização do instrumento nos estágios iniciais e aumentar a probabilidade de obtenção de validade de construto de suporte nos estágios posteriores. A validade de conteúdo mostra até que ponto uma medição empírica reflete um domínio específico de conteúdo (Furr, 2021; Heale \& Twycross, 2015; Pasquali, 2013; Rust et al., 2020).

A literatura na área de desenvolvimento de instrumentos para mensuração de construtos psicológicos recomenda que, no processo de construção do instrumento preliminar, a operacionalização do construto deve ser o mais abrangente possível (Fur, 2021; Pasquali, 2013). No caso do instrumento que se pretende validar preliminarmente neste estudo, a quantidade de cenas de ataque selecionadas abrange o maior número de situações possíveis que acontecem no jogo de basquetebol feminino e que demandam o processo decisório do jogador que se encontra no ataque com a posse de bola. Etapas posteriores como validade de construto, validade de critério e confiabilidade são necessárias para incrementar a robustez psicométrica do instrumento, ou seja, para garantir que o instrumento mensure o construto psicológico pretendido (Heale \& Twycross, 2015; Rust et al., 2020)

Salienta-se que o atual estudo é pioneiro, no melhor do conhecimento, em contar com cenas editadas de jogos de basquetebol feminino profissional e validadas no que se refere ao conteúdo, o que possibilita a realização de estudos de intervenção por meio do desenvolvimento de programas de treinamento perceptivo, especialmente no universo feminino. Estudos no basquetebol utilizaram cenas editadas de jogos para a realização de programas de treinamento perceptivo. Os resultados confirmaram a efetividade desses programas no aprimoramento da tomada de decisão (Alarcón et al., 2011; Iglesias et al., 2005; Pagé et al., 2019).

No basquetebol a mensuração do conhecimento tático declarativo permite inferências sobre o nível de compreensão tática que o atleta detém sobre o jogo, o que possibilita o planejamento dos objetivos, estruturação dos conteúdos e avaliação do processo de ensinoaprendizagem-treinamento (E-A-T). O desenvolvimento e validação de um teste de conhecimento tático declarativo para o basquetebol feminino é um processo importante para futuras avaliações e prescrições do processo pedagógico, o que auxilia o professor na decisão sobre qual modelo de ensino é o mais adequado para o planejamento e estruturação das atividades. O desenvolvimento e a validação do IMCTD-BF permitirão também futuras investigações relacionando-se o conhecimento tático declarativo com outras variáveis intervenientes à tomada de decisão, como: o conhecimento tático processual, esforço cognitivo e experiência competitiva.

\section{Considerações finais}

$\mathrm{O}$ atual estudo mostra um avanço no que tange a construção de um instrumento que mensura o conhecimento tático declarativo para o basquetebol feminino. Observa-se na literatura especializada que, no geral, o processo de desenvolvimento e construção de instrumentos para mensuração do conhecimento tático declarativo no basquetebol, por meio de cenas de vídeo extraídas de jogos oficiais, não apresentam evidências satisfatórias e robustas sobre a validade de conteúdo, de acordo com os procedimentos psicométricos presentes na literatura (Furr, 2021; Hernández-Nieto, 2002; Pasquali, 2013). Tal situação pode influenciar nos resultados de estudos que investigaram questões relativas à tomada de decisão no esporte. Apenas o estudo de Reis e Morales (2020) apresentaram evidências concretas de validade de conteúdo de cenas para a construção de um teste de conhecimento tático declarativo. Porém tal estudo focou no universo do basquetebol masculino.

Considera-se como limitação do estudo a mensuração do conhecimento tático declarativo no basquetebol apenas por meio de cenas de ataque, ou seja, são necessários novos estudos que verifiquem a compreensão tática a partir de ações dos jogadores na defesa.Além disso não se considerou o placar, bem como a situação do jogo que cada cena de ataque representava. O estudo se delimita a avaliação de cenas a partir de partidas profissionais de equipes femininas, ou seja, as cenas são destinadas para a mensuração do conhecimento tático declarativo no basquetebol para pessoas do sexo feminino. No início das disputas competitivas, tanto nas categorias de base quanto na categoria profissional, ocorre a divisão por sexo na modalidade basquetebol. Ressaltase que a velocidade das ações motoras dos atletas e o predomínio das ações técnico-táticas são diferentes nas partidas de equipes masculinas e femininas. Assim, não é viável, nesse momento, construir e validar o mesmo teste para ambos os sexos. 
Os resultados comprovaram as evidências de validade de conteúdo de um número satisfatório de itens (cenas) para a criação de um instrumento de avaliação do conhecimento tático declarativo no basquetebol feminino, já que tais cenas atenderam a pressupostos de validação de conteúdo de instrumentos psicométricos. A mensuração do conhecimento tático declarativo em atletas do basquetebol feminino permite que os treinadores façam inferências a respeito da compreensão tática das atletas, o que pode subsidiar os conteúdos a serem trabalhados no processo de ensino-aprendizagemtreinamento (E-A-T).

\section{Referências}

Aburachid, L. M., Morales, J. C., \& Greco, P. J. (2013). Test validation process of tactical knowledge in tennis: The influence of practice time and competitive experience. Internation Journal of Sports Science, 3(1), 13-22.

Alarcón, F., Vélez, D., Léon, M. T., Ortin, N. U., \& López, M. I. (2011). Influencia del programa de entrenamiento reflexivo sobre el conocimiento declarativo de un equipo de baloncesto. Cuadernos de Psicología del Deporte, 11(1), 19-28. Recuperado em 15 Mar. 2020: https://revistas.um.es/cpd/article/ view/120931

Anderson, J. R. (2005). Aprendizagem e Memória - Uma Abordagem Integrada - $2^{a}$ Edição. Rio de Janeiro: LTC, 2005.

Cassepp-Borges, V., Balbinotti, M. A., \& Teodoro, M. L. (2010). Tradução e validação de conteúdo: Uma proposta para adaptação de instrumentos. In L. Pasquli (Ed.) Instrumentação Psicológica: Fundamentos e práticas (pp. 506-520). Porto Alegre: Artmed.

Castro, H. O., Costa, G. C., Praça, G. M., Campbell, C. S., \& Greco, P. J. (2017). Análise das fixações visuais e tomada de decisão de atletas de voleibol das categorias infanto e juvenil. Revista Brasileira de Ciência e Movimento, 25(1), 51-59. Recuperado em 15 Mar. 2020: https://portalrevistas.ucb.br/ index.php/RBCM/article/view/6337

Caicedo, S. A., \& Vargas, M. A. C. (2020). Diseño y validación de un instrumento observacional para la valoración de acciones tácticas ofensivas en fútbolvatof. Retos: nuevas tendencias en educación física, deporte y recreación, (38), 306-311. https://doi.org/ $10.47197 /$ retos.v38i38.76622

Costa, G. C., Castro, H. O, Cabral, F. A., Morales, J. P., \& Greco, P. J. (2016). Content validity of scenes of the declarative tactical knowledge test in volleyball - DTKT: Vb. Revista Brasileira de Cineantropometria e Desempenho Humano, 18(6), 629-637. Recuperado em 15 Mar. 2020: https://portalrevistas.ucb.br/ index.php/RBCM/article/view/6337

French, K. E., \& Thomas, J. (1987). The relation of knowledge development to children's basketball performance. Journal of Sport Psychology, 9, 15-32.

Furr, M. R. (2021). Psychometrics: an introdution. 4 ed. Thousand Oaks: Sage.

Gamero, M.G.; González-Espinosa, S.; Ibáñez S.J.; Feu, S. (In Press) Instrument for measurement of declarative and procedural knowledge in basketba1l. Revista Internacional de Medicina y Deporte.

García-Ceberino, J. M., Gamero, M. G., Feu, S., \& Ibáñez, S. J. (2020). Experience as a determinant of declarative and procedural knowledge in school football. International journal of environmental research and public health, 17(3), 1063. https://doi.org/ 10.3390/ijerph17031063

Gréhaigne, J. F., \& Godbout, P. (1995).Tactical knowledge in team sports from a constructivist and cognitivist perspective. Quest, 47(4), 490-505.

Heale, R., \& Twycross, A. (2015). Validity and reliability in quantitative studies. Evidence-Based Nursing, 18(3), 66-67. http:/ /dx.doi.org/10.1136/eb-2015-102129 Hernández-Nieto, R.A. (2002). Contributions to Statistical Analysis. Mérida: Universidad de Los Andes.

Iglesias, D. G., Rivas, D. S., Calvo, T.G., Gimeno, E. M., \& Álvarez, F. V. (2005) Influencia de un programa de supervisión reflexiva sobre la toma de decisiones y la ejecución del pase en jóvenes jugadores de baloncesto. Revista de Psicología del Deporte, 14(2), 209-223. Recuperado em 12 Mar. 2020: https:// www.rpd-online.com/article/view/182

Kump, B., Moskaliuk, J.; Cress, U., \& Kimmerle, J. (2015). Cognitive foundations of organizational learning: Re-introducing the distinction between declarative and non-declarative knowledge. Frontiers in Psychology, 1489(6), 1-12. https: / / doi.org/ 10.3389/fpsyg.2015.01489

Llerena, A. M., Blanco, P. J. C., \& Hernández, E. (2020). Diseño, validación y fiabilidad de un instrumento de evaluación del comportamiento táctico en mini voleibol. Retos: nuevas tendencias en educación física, deporte y recreación, (38), 661-666. https://doi.org/ 10.47197/retos.v38i38.77792

Leão, I. C. (2015). Validação e aplicação de um protocolo do nível de conhecimento tático declarativo no handebol. Tese (Doutorado em Neuropsiquiatria e Ciências do 
Comportamento) - Universidade Federal de Pernambuco, Recife.

Mcpherson, S. L. (1994). The Development of Sport Expertise: Maping the tactical domain. Quest, 46, 223-240.

Minayo, M. C (2012). O desafio do conhecimento: pesquisa qualitativa em saúde. São Paulo: Hucitec.

Pagé, C., Berniera, P., \& Trempe, M. (2019). Using video simulations and virtual reality to improve decision-making: Skills in basketball. Journal of Sports Science. 37(21), 1-7. DOI: 10.1080/ 02640414.2019 .1638193

Pasquali, L. (2013). Psicometria: Teoria dos testes na psicologia na educação (5 ed.). Petrópolis, RJ: Vozes.

Pasquali, L. (2007). Validade dos testes psicológicos: Será possível reencontrar o caminho? Psicologia: Teoria e Pesquisa. 23, 99-107. Recuperado em 12 Mar. 2020: http:/ /www.scielo.br/pdf/ptp/v23nspe/18.pdf

Pasquali, L. (2010). Testes referentes a construto: Teoria e modelo de construção. In: Pasquali, L. (Org.) Instrumentação Psicológica: fundamentos e práticas. (pp. 165-198). Porto Alegre: Artmed.

Raab, M. (2003). Decision making in sport: Influence of complexity on implicit and explicit learning. International Journal of Sport and Exercise Psychology, 1(4), 406-433.

Raab, M. (2015). SMART-ER: A situation model of anticipated response consequences in tactical decisions in skill acquisition-Extended and revised. Frontiers in Psychology, 5, 1-5. DOI: 10.3389/ fpsyg. 2014.01533
Reis, C. P., Morales, J. C. (2020). Validade de conteúdo da versão preliminar do instrumento para mensurar o conhecimento tático declarativo no basquetebol. Revista Brasileira de Psicologia do Esporte, 10(2), 200217, 2020. http://dx.doi.org/10.31501/ rbpe.v10i2.11639

Ribeiro, L., Figueiredo, L., Morales, J., Nascimento, G., Porto, D., \& Greco, P. (2021). Tactical knowledge and visual search analysis of female handball athletes from different age groups. Journal of Physical Education and Sport, 21(2), 948 - 955. https: / /doi:10.7752/ jpes.2021.02118

Rust, J., Kosinski, M., Stillwell, D. (2020). Modern psychometrics: The science of psychological assessment. Routledge.

Smeeton, N. J., Hüttermann, S., \& Williams, M. (2019). Postural cues, biological motion perception, and anticipation in sport. In M.Williams \& R. C. Jackson, R.C. (Eds). Anticipation and decision making in sport (pp. 4-24). New York: Routledge.

Sternberg, R. J., \& Sternberg, K. (2016). Cognitive Psychology, (7th ed.). Wadsworth Publishing.

Tenenbaum, G., \& Medeiros Filho, E. (2017). Decisionmaking in sports: A cognitive and neural basis perspective. In Reference Module in Neuroscience and Biobehaviour Psychology (pp. 1-19). Elsevier.

Thomas, J. R., Nelson, J. K., \& Silverman, S. J. (2012). Métodos de Pesquisa em Educação Física. Porto Alegre: Editora Artmed.

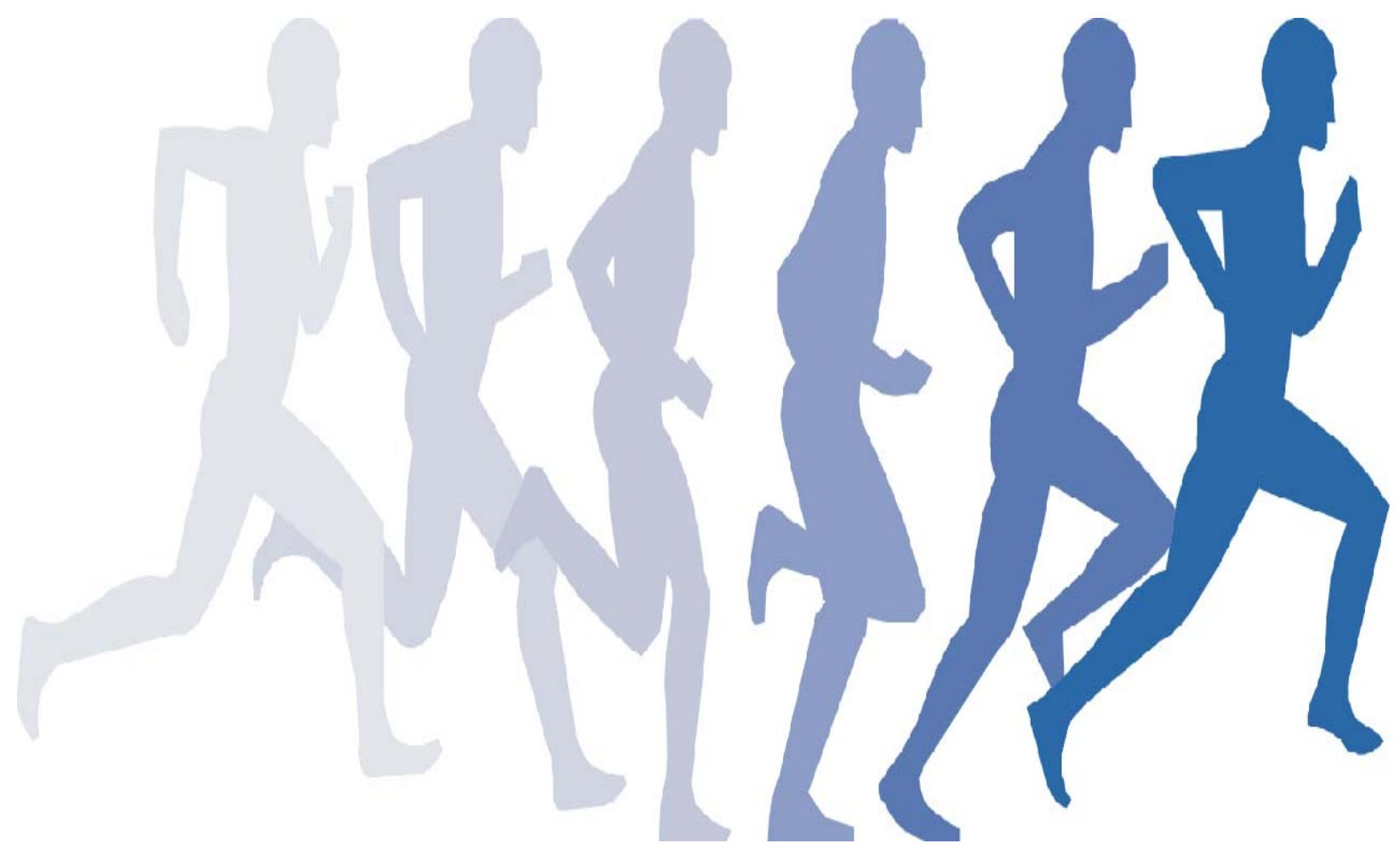

